\title{
O processo de aprendizagem na educação online para a configuração do espaço híbrido
}

\author{
The learning process in online education for the configuration of \\ the hybrid space
}

\author{
Luciana Backes ${ }^{1}$ \\ Renati Fronza Chitolina ${ }^{2}$ \\ Eduardo Lorini Carneiro ${ }^{3}$
}

Resumo: O desenvolvimento e a socialização das tecnologias digitais (TD) provocam a configuração de espaços digitais virtuais, segundo Backes (2007; 2011; 2013; 2015), nos espaços geograficamente localizados, rompendo fronteiras e configurando espaços híbridos, conforme Latour (1991) e Santos (2008). Assim, emerge a questão: Como se desenvolve o processo de aprendizagem na educação online para a configuração do espaço híbrido? A reflexão ocorre na pesquisa "Os Espaços Híbridos nos Processos de Ensinar e de Aprender: A presença e a copresença no viver e conviver" e por meio do Estudo de Caso sobre disciplinas da modalidade EaD na Universidade La Salle - Canoas, com natureza exploratória e abordagem qualitativa. O processo de aprendizagem é analisado a partir da presença dos estudantes manifestada nos registros das atividades, por meio das unidades de análise:

\footnotetext{
${ }^{1}$ Graduada em Pedagogia Habilitação Magistério e Séries Iniciais pela Universidade do Vale do Rio dos Sinos (1996), especialização em Informática na Educação pela Universidade Federal do Rio Grande do Sul (2002), mestrado em Educação pela Universidade do Vale do Rio dos Sinos (2007) e doutorado em Educação pela Universidade do Vale do Rio dos Sinos (2011) e Sciences de l'Education pela Université Lumière Lyon 2 (2011). Bolsa de Estágio Pós-Doutoral no Exterior CAPES, na l'Université Paris Descartes Paris V - Sorbonne (20132014).

2 Graduada em Ciências Biológicas (LP/B) pela Universidade de Passo Fundo (UPF, 2007). Especialista em Ciências Ambientais e Conservação da Biodiversidade pela Universidade Regional Integrada do Alto Uruguai e das Missões (URI, 2009). Mestre em Ensino Científico e Tecnológico de Ciências pela Universidade Regional Integrada do Alto Uruguai e das Missões (URI, 2014). Doutora em Educação pela Universidade La Salle - Canoas (2020). ${ }^{3}$ Graduado em Geografia Licenciatura (2010) e Bacharelado (2012) pela Universidade Luterana do Brasil. Especialista em Ensino de Sociologia para Professores do Ensino Médio pela Universidade Federal do Rio Grande do Sul (2015). Mestre em Educação pela Universidade La Salle -Canoas (2019).
}

Interfaces da Educ., Paranaíba, v.11, n.32, p. 542 - 570, 2020 
ação (presença), perturbação, interação, legitimação do outro, configuração do espaço híbrido e superação (significado no cotidiano). Os resultados evidenciam a importância da problematização dos conhecimentos como potencializadora do processo de interação. No compartilhamento dos registros é fundamental a legitimidade dos estudantes para a configuração do espaço híbrido, em uma convivência que é própria e particular a cada grupo.

Palavras-chave: Processo de aprendizagem. Espaço híbrido. Educação online.

\section{Abstract}

The development and socialization of digital technologies (DT) cause the configuration of virtual digital spaces, according to Backes (2007; 2011; 2013; 2015), in geographically located spaces, breaking borders and configuring hybrid spaces, according to Latour (1991) and Santos (2008). Thus, the question: How does the learning process in online education develop for the configuration of the hybrid space? The thought happen in research "Hybrid Spaces in the Processes of Teaching and Learning: The presence and co-presence in living and coexisting", through the Case Study on disciplines of distance education in La Salle University - Canoas, with an exploratory nature and a qualitative approach. Based on the student's presence manifested in the records carried out in the proposed activities, the units of analysis explored for the learning process are: action (presence), disturbance, interaction, legitimation of the other, configuration of the hybrid space and overcoming (meaning in everyday life). The results show the importance of problematizing knowledge, as an element that enhances the interaction process. When sharing records, students need to be considered as someone with whom they can learn, configuring the hybrid space, for coexistence that is specific to this group.

Key-Words: Learning process; Hybrid space; Online education. 


\section{Introdução}

Atualmente, o viver e o conviver são ampliados de forma significativa, principalmente com o desenvolvimento e a socialização de TD, onde são configurados os espaços digitais virtuais. Portanto, outras formas de viver e conviver são estabelecidas, modificando as ações e as experiências, constituindo novas culturas, ressignificando conceitos e desenvolvendo novos processos de ensinar e de aprender, tensionados pelo sociólogo Santos (2004) ao sublinhar os avanços e as catástrofes que se impõe na contemporaneidade.

Segundo Backes, Schlemmer e Ratto (2017), identificamos o movimento de retorno dos laços sociais estabelecidos por meio dos interesses, do afeto e da emoção, considerados elementos chave na reconstituição das agregações, o "estar juntos", através das comunidades ou, conforme Maffesoli (2012), das tribos. Essas tribos se constituem de diferentes maneiras e em diversas dimensões, tanto em espaços digitais virtuais - por meio de mídias sociais, ambientes virtuais de aprendizagem, metaversos e até mesmo em jogos massivos online - assim como em espaços geograficamente localizados - parques, escolas, universidades, empresas, ruas etc. Nesse viver e conviver, percebe-se que os espaços digitais virtuais estão cada vez mais presentes e articulados aos espaços geograficamente localizados, configurando um espaço cada vez mais híbrido.

A partir dessas transformações emerge a tensão sobre: Como se desenvolve o processo de aprendizagem na educação online para a configuração do espaço híbrido? No contexto do grupo de pesquisa COTEDIC UNILASALLE/CNPq, foi desenvolvido o projeto de pesquisa "Os Espaços Híbridos nos Processos de Ensinar e de Aprender: A presença e a copresença no viver e conviver" 4 , a fim de refletir sobre o processo de aprendizagem dos estudantes na educação online para a configuração do espaço híbrido e

\footnotetext{
${ }^{4}$ Projeto aprovado no Comitê de Ética em Pesquisa CAAE: 35560414.8.0000.5307 Interfaces da Educ., Paranaíba, v.11, n.32, p. 542 - 570, 2020
} 
avançar no desenvolvimento da modalidade $\mathrm{EaD}$, tão criticada por diferentes profissionais.

No desenvolvimento das disciplinas na modalidade EaD, identifica-se que os vocabulários "presença" e "proximidade" estão diretamente relacionados aos modelos mentais construídos ao longo da vida dos estudantes, a partir da significação de estar junto, ao lado de alguém fisicamente presente, no mesmo tempo e espaço. Assim, há uma associação direta ao corpo físico a noção de "estar presente" e de "estar próximo". No entanto, Trein (2010), comenta que os sentimentos de presença e de proximidade, por mais associados que estejam ao corpo fisico, também surgem de outras formas como olhar fotografias ou ouvir músicas que remetem às lembranças. Nesse sentido, a presença tem uma conotação simbólica, ou seja, uma representação por meio de um signo (significante e significado). Essa sensação de ter o outro por perto, por meio dos signos, dos sentidos, da imaginação é o primeiro tipo de presença virtual que conhecemos, pois "o virtual é o que existe em potência não em ato" segundo o filósofo Lévy (1996, p. 15).

Assim, é possivel compreender que o conceito de presença e de proximidade em disciplinas na modalidade $\mathrm{EaD}$, quando associado ao uso de TD, principalmente às de informação, de comunicação e de interação, incluindo as digitais virtuais, bem como aos serviços de telecomunicação, precisa ser (re)significado, ampliado, transformado, fazendo emergir outros conceitos como telepresença, presença digital virtual, dentre outros. Nesses espaços digitais virtuais é possivel vivenciar um tipo de experiência mediada, que cria um forte sentido de presença, segundo Lombard e Ditton (1997), e podem ser percebidas como "natural", "imediata", "direta" e "real". Nas TD, bem como os demais meios de comunicação tradicionais, a presença é propiciada em um menor grau de intensidade em relação aos sentimentos e às sensações.

A nossa existência em diferentes espaços se efetiva, normalmente, quando compartilhada com o outro, pois para se sentir presente precisamos 
da legitimação da nossa presença pelo outro, principalmente quando falamos em espaços digitais virtuais, online e dinâmicos. A presença compartilhada é denominada de copresença e ocorre quando em um espaço, fazem presentes duas ou mais realidades diferentes. Assim, para os geógrafos Lévy e Lussault (2003), nesse espaço temos um conjunto e/ou uma agregação de realidades diferentes e que torna possível a interação.

A ressignificação da compreensão de presença e copresença remete à reflexão sobre os aspectos relevantes do processo de aprendizagem, a partir de Maturana e Varela (2001), considerando a educação online conforme Silva (2014), Santos e Weber (2014), Santos (2009) e Santos e Silva (2009), desenvolvida em espaços digitais virtuais, segundo Backes (2007; 2011; 2013; 2015) e em espaços híbridos (digitais e geográficos) conforme Latour (1991) e Santos (2008). Essa pesquisa é delineada no estudo de caso envolvendo disciplinas da graduação e pós-graduação, cuja a análise de dados foi submetida à análise de conteúdo por meio das unidades: perturbação, interação, legitimação do outro, configuração do espaço de convivência e superação.

Em seguida serão tratadas as reflexões sobre as ações dos estudantes (presença), perturbações instauradas no processo de aprendizagem por meio do compartilhamento, da interação e da legitimação do outro para superação das perturbações e das tensões na configuração do espaço híbrido, rompendo as fronteiras entre os espaços geograficamente localizados e os espaços digitais virtuais. Por fim, a sistematização sobre o processo de aprendizagem na configuração do espaço híbrido e reflexão sobre as possibilidades de aprendizagem dos estudantes.

\section{O processo de aprendizagem na educação online}

O sociólogo Santos (2004) ao sublinhar as tensões vivenciadas na contemporaneidade, anuncia a emergência de novos paradigmas. A concepção paradigmática emergente exige uma concepção epistemológica coerente, ou seja, uma concepção epistemológica que explique sobre como os 
seres humanos constroem os conhecimentos. Assim, podemos pensar os pressupostos da educação na perspectiva da emancipação desse ser humano que vive na contemporaneidade de acordo com Backes e Schlemmer (2014) e Schlemmer, Backes e La Rocca (2016). Para as reflexões desse artigo optouse pela teoria da Biologia do Conhecer de Maturana e Varela (2001; 1997), pois compreende o processo de aprendizagem num cenário emergente a partir do pensamento sistêmico, caracterizado pela participação, autonomia, relações e interações, perturbações, flexibilidade e cooperação entre homens e mulheres que respeitam a si e ao outro no compartilhar.

Segundo Maturana e Varela (2001), a aprendizagem consiste em se autoproduzir por meio de processos de transformação recorrente, ou seja, ocorre aprendizagem quando o ser humano se modifica a partir da sua história de interações com outros seres humanos e em congruência com o meio. Os seres humanos, devido a sua capacidade autônoma ${ }^{5}$, identificam perturbações nos processos de interação realizados no cotidiano e, por meio da sua autopoiese ${ }^{6}$, compensam essas perturbações.

$\mathrm{Na}$ interação entre os sujeitos (seres humanos) emerge o desequilibrio (perturbação), em relação a um objeto de conhecimento, atravessadas pelo contexto social, cultura, história e emocional. Para compensar a perturbação, os seres humanos buscam novos elementos, constroem hipóteses, compartilham seus conhecimentos prévios e constroem novos conhecimentos, configurando o espaço de convivência entre os participantes. Apesar do caráter coletivo no processo de interação, cada ser humano aprenderá de forma única, relacionada às estruturas (ontogenia), em

5 [...] encontramos os sistemas vivos como unidades autônomas, surpreendentemente diversas, dotadas de capacidade de reproduzir-se. Nestes encontros, a autonomia é tão obviamente um aspecto essencial dos sistemas vivos que sempre que se observa algo que parece ser autônomo a reação espontânea é considerá-lo vivente. Porém, ainda que revelada continuamente na capacidade homeostática dos sistemas vivos de conservar sua identidade através da compensação ativa das deformações [...] (MATURANA; VARELA, 1997, p. 65).

${ }^{6}$ La palabra autopoiesis viene de los vocablos griegos autos, que quiere decir sí mismo, y poiesis, que quiere decir producir. Al caracterizar a los seres vivos como sistemas autopoieticos estamos diciendo que los seres son sistemas que se caracterizan como sistemas que se producen a sí mismo continuamente. En otras palabras, lo que decimos que la palabra autopoiesis es que los seres vivos son redes de producciones moleculares en las que las moléculas producidas generan con sus interaciones la misma red que las produce (MATURANA, 1999, p. 93).

Interfaces da Educ., Paranaíba, v.11, n.32, p. 542 - 570, 2020 
congruência com o meio em que está inserido. A aprendizagem, nesta perspectiva, ocorre quando há a transformação dos seres humanos em interação e do objeto de conhecimento.

Para Backes (2011), no processo de aprendizagem, mobilizam-se cinco aspectos importantes: o ser humano (sujeito); o conhecimento (objeto); a perturbação; a interação; e o meio (contexto). Assim, ao considerar a aprendizagem em espaços digitais virtuais (meio/contexto), é indispensável (re)significar estes cinco aspectos mencionados.

O ser humano participa e se faz presente a partir de diferentes maneiras nos espaços digitais virtuais, compartilha seus conhecimentos por meio de múltiplas linguagens e articula com suas histórias de interações vivenciadas também em espaços geográficos. A interação pode se dar de maneira abrangente entre os seres humanos, ser humano e conhecimento, ser humano e espaço digital virtual e, de maneira dinâmica, por meio da articulação entre espaços digitais virtuais e espaços geográficos, mas em todos os momentos ela se dá por meio de perturbações em relação ao objeto de conhecimento.

O processo de interação, segundo Maturana (1993a, 1993b, 1999), ocorre em um espaço de convivência onde o ser humano compartilha sua percepção e perspectiva de ser humano, por meio de contínuas transformações com o outro e em congruência com o meio. Logo, as interações que ocorrem ao longo da vida entre os seres humanos, o meio e/ou o objeto de conhecimento fundamentam a compreensão "Todo fazer é um conhecer e todo conhecer é um fazer" (MATURANA; VARELA, 2001, p. 31). Desta forma, os seres humanos atuam de maneira dialética, sendo, em diferentes momentos, coensinantes, coaprendentes e/ou comediadores.

A construção do conhecimento é o resultado da ação conjunta de todos os aspectos mencionados anteriormente, isto é, uma ação social, ao atribuir significados ao objeto de conhecimento no cotidiano, ampliando ou construindo novos conhecimentos, segundo Backes (2011). Assim, "Educar es crear, realizar, y validar en la convivencia, un modo particular de convivir. 
Esto siempre se realiza en una red de conversaciones que coordina el hacer y el emocionar de los participantes" (MATURANA, 1999, p. 147).

A educação se efetiva, quando: o ser humano age em relação ao objeto de conhecimento em congruência com o meio em que está inserido; a capacidade de reflexão é ativada por meio do conhecimento que perturba as estruturas do ser humano e essa perturbação é compensada na interação com o outro; o ponto de vista de um ser humano é ampliado na mesma medida em que amplia o seu conhecimento, estabelecendo relações com outros conhecimentos e relacionando com o contexto em que está inserido; e configura o espaço de convivência com o outro.

Nesta perspectiva, pode-se pensar a educação online para além da educação a distância $(\mathrm{EaD})^{7}$. Maturana (1999) compreende a educação a distância como um espaço possibilitador de viver e conviver de maneira conversacional a fim de emergir a diversidade existente. Portanto, envolve a construção de projetos comuns entre diferentes pessoas, independente da sua origem, o que valida todos os participantes (estudantes e educador), aceitando sua história cultural como ponto de partida legítimo para o desenvolvimento dos estudos. Isto implica também, em considerar os conhecimentos já construídos pelos estudantes, respeitar o ritmo de aprendizagem de cada um e conservar a legitimidade do estudante numa dinâmica entre o coaprendente e o coensinante.

La educación a distancia, cuando es aceptada y acogida, permite una modificación Del escuchar, ver y hacer, en la convivencia del país; es decir, de su espacio psíquico, de una manera que permite la cooperación a cualquier nivel, ya que salta, en su efectividad valorizada del individuo, todas las barreras culturales, de clase, y económicas. Es decir, permite ampliar la realización del vivir democrático (MATURANA, 1999, p. 149).

7 Conforme Backes e Mantovani (2017, p. 97-98) "A educação a distância é definida, conforme o Decreto $\mathrm{n}^{\circ}$ 5.622, de 19 de dezembro de 2005, como uma modalidade educacional que ocorre por meio da mediação didático-pedagógica nos processos de ensino e aprendizagem e com a utilização das Tecnologias de Informação e Comunicação, aqui denominadas de TD, com estudantes e professores que não se encontram num mesmo espaço geográfico". No contexto da lei, identifica-se que essa modalidade denominada de $\mathrm{EaD}$, pode designar tanto ensino a distância, quanto educação a distância. Embora, o significado de Ensino e Educação sejam diferentes, muitas vezes são considerados sinônimos. 
A abordagem de Maturana (1999) ultrapassa as definições da EaD, numa perspectiva mais próxima da educação online. A educação online consiste no "conjunto de ações de ensino-aprendizagem ou atos de currículo mediados por interfaces digitais que potencializam práticas comunicacionais interativas e hipertextuais", conforme a educadora Santos (2009, p. 5663). As práticas se efetivam na configuração de espaços digitais virtuais, disponiveis online, no

\begin{abstract}
uso de ambientes virtuais de aprendizagem, que são um híbrido entre objetos técnicos e seres humanos em processo de comunicação em rede, podemos desenvolver conteúdos, situações de aprendizagem e dispositivos de pesquisa que lancem mão de diversas interfaces, ou seja, de canais de comunicação entre os sujeitos e os conhecimentos produzidos, compartilhados e negociados pelo mesmo ambiente virtual de aprendizagem. (SANTOS; WEBER, 2014, p. 1314)
\end{abstract}

Para que a educação online se efetive nesta perspectiva, o educador é considerado o mediador e coparticipante deste processo, assumindo diferentes funções como problematizador, articulador e orientador da aprendizagem dos estudantes na medida em que tem a compreensão complexa sobre a construção do conhecimento. Assim, o educador é também aprendente ao compreender sobre como cada estudante aprende, ou seja, o educador aprende sobre o aprender do estudante.

O estudante é o sujeito da aprendizagem em permanente ação cognitiva, envolve-se nas práticas para uma aprendizagem na modalidade interativa, conforme Silva (2014) caracterizado pela abertura ao inesperado, junções não lineares (hipertextuais), interações múltiplas, construções de roteiros originais e colagens, abertura para novas redes de relações e autoria-coautoria. Assim, na relação entre educador, estudante e conhecimento "coexistem múltiplos centros" (p. 93).

Quem educa, também aprende, transforma-se no próprio ato de educar, na relação que se estabelece entre professor e aluno. O aprendiz, por sua vez, ao aprender, também educa, com base na unidualidade existente na relação educador-educando e educando- 
educador. Ao falar do educador, reconhecemos sua posição de educando e vice-versa. (MORAES, 2004, p. 150)

$\mathrm{Na}$ ação do educador-educando constroem-se conhecimentos na criação de diferentes redes. Logo, conforme Santos e Silva (2009) na educação online articula-se os conhecimentos de maneira interdisciplinar, a partir da ação dos aprendentes e dos ensinantes de maneira dialógica e interativa. Portanto, conteúdo (conhecimento), não é apresentado como transmissão, mas proposto como redes de provocações à autoria e coautoria.

\section{A configuração dos espaços híbridos}

Conforme Backes (2007, 2011 e 2015) a noção de espaço é objeto de estudo da Geografia, no entanto, as demais áreas do conhecimento se apropriam dessa noção e fazem, consequentemente, suas ressignificações. Para a compreensão dos espaços híbridos na contemporaneidade as ressignificações iniciam com a noção de espaço, definida pelo geógrafo Santos (1980, p. 122):

\footnotetext{
o espaço se define como um conjunto de formas representativas de relações sociais do passado e do presente e por uma estrutura representada por relações sociais que estão acontecendo diante dos nossos olhos e que se manifestam através de processos e funções. O espaço é, então, um verdadeiro campo de forças cuja aceleração é desigual. Daí porque a evolução espacial não se faz de forma idêntica em todos os lugares.
}

Então, o espaço é compreendido como a totalidade entre seres humanos, sociedade, objetos, funções, processos do passado e processos do presente. Ou seja, uma configuração complexa que ocorre nas relações, interações e articulações de tudo que está implicado no viver. Para Santos (2008), um conjunto de fixos (nas relações territoriais) e fluxos (por meio das relações ambientais, culturais e sociais). Lembrando que, para o autor, "a configuração territorial não é o espaço, já que a sua realidade vem da sua materialidade, enquanto o espaço reúne a materialidade e a vida que a anima" (p. 38). 
A compreensão de território, para Santos (2014), deriva das relações de poder entre os seres humanos. O espaço reúne o território com as subdimensões de região (organizações sem o estabelecimento de relações de poder diretas); paisagem (materialidade do espaço compreendido a partir dos sentidos); e lugar (as relações sociais estabelecidas entre os seres humanos nos espaços e entre e os seres humanos e os próprios espaços). Logo, a convivência entre os seres humanos é resultado dessas interações e relações, nas quais convergem diferentes formas de se organizar no espaço, tornandoo cada vez mais híbrido.

Numa perspectiva próxima, Maturana (2002) trata o viver e conviver a partir da dinâmica estabelecida, por meio da configuração do espaço de relação. Assim, o espaço de relação se configura a partir desse viver cotidiano com o outro; da aceitação do outro como legítimo; da construção de condutas comuns que estabilizam, conservam ou mudam as formas de viver e conviver em comunidade e do operar do ser humano, em sua totalidade orgânica, psíquica, mental e cultural, em relação às significações atribuídas a partir do viver com o outro. Desta forma, compreende-se que os espaços de relação são configurados territorialmente, por meio de uma existência material, e, socialmente, por meio das condutas construídas no viver atribuindo significados, conforme Santos (2008).

Na contemporaneidade, se evidencia a configuração de outros espaços, como o espaço digital virtual. Para Backes $(2011,2013,2015)$ são as TD que possibilitam a representação da percepção, a relação e a interação entre os seres humanos, considerando também a comunicação, a conectividade e a ubiquidade. Assim, as TD podem ser compreendidas como espaço enquanto: representação das relações territoriais (natureza e matéria) e sociais (passado, presente e futuro); estrutura do momento atual vivido (processos e funções pertencentes ao nosso espaço); campo de força de ações (portanto desiguais).

Segundo Backes $(2007 ; 2011)$, as TD podem ser consideradas como espaços digitais virtuais, quando: possibilitam a ação, relação, interação e 
compartilhamento das representações dos seres humanos; são configurações próprias e particulares de cada grupo social (os seres humanos estão em congruência com o meio); potencializam a coordenação das coordenações das ações ${ }^{8}$ (os seres humanos compreendem as ações articuladas pelo outro e atribuem significados). Portanto, nem todas as TD são consideradas espaços digitais virtuais, hardwares e softwares tais como: ambiente virtual de aprendizagem, ambiente em realidade virtual, metaverso (mundo digital virtual em 3D- MDV3D), comunicador instantâneo, jogo, simulador, weblog, wiki, correio eletrônico, agente comunicativo, telefone, dentre outros. Nesse contexto, se inclui o peopleware, que organiza comunidade virtual de aprendizagem, de prática e de relacionamento e/ou mídias sociais.

No âmbito da educação online, são considerados espaços digitais virtuais as TD que possibilitam a ação, interação e protagonismo dos participantes. Normalmente, elas são utilizadas em um conjunto, por meio de links, de conectividade e de mobilidade entre as diferentes TD, dando a impressão de ser uma única tecnologia, integrada e articulada. Desta forma, se cria e se recria a perspectiva do hibridismo tecnológico digital conceituado por Backes (2015) que consiste na mistura, cruzamento, integração e articulação de diferentes TD, para além da sua coexistência, ou seja, na configuração de um espaço formado por vários espaços.

Com o desenvolvimento e a socialização das TD, num híbrido entre ser humano, técnica e máquina, propomos um outro modo de ver a realidade. Uma realidade que nunca foi pura, segundo Latour (1991). Para Santos (2008), atualmente não é possivel distinguir onde termina a obra da natureza e onde começa a obra do homem, ou ainda, indicar onde termina o técnico e onde começa o social. Portanto, o hibridismo consiste em misturar objetos de tal forma que não podem ser explicados separadamente, o que

8 Segundo Maturana (2002) a coordenação da coordenação consiste numa sucessão particular de coordenações de ações no próprio viver, orientando o viver a partir das interações internas da dinâmica e não como algo externo. Assim a coordenação da coordenação implica em interações que resultam em uma orientação para a orientação do viver. 
nos leva a acreditar que estamos vivendo uma nova ecologia, um novo ecossistema integrando seres vivos, máquinas e culturas.

Nesse contexto híbrido, os seres humanos constituem o viver com o outro, também em espaços digitais virtuais por meio de máquinas, assim, configurando os espaços digitais virtuais de convivência. Essa configuração também ocorre por meio dos espaços geográficos, invalidando a ideia de mundos paralelos ou segunda vida.

\section{Metodologia de pesquisa}

A pesquisa "Os Espaços Hibridos nos Processos de Ensinar e de Aprender: A presença e a copresença no viver e conviver", se insere no contexto da linha de pesquisa Culturas, Linguagens e Tecnologias na Educação, do Programa de Pós-Graduação em Educação da Universidade La Salle - Canoas. A natureza exploratória da pesquisa se justifica em experimentar vários espaços para a formação na educação online, que se configura em diferentes contextos, visando o processo de interação e o compartilhamento da presença e copresença, entre os estudantes, ultrapassando as fronteiras acadêmicas no processo de aprendizagem.

A abordagem da pesquisa é qualitativa, por meio de um Estudo de Caso, pois envolve a observação direta dos acontecimentos que se efetivaram nas atividades realizadas na disciplina de Informática e Multimeios na Educação ofertada para a graduação com 76 estudantes e as disciplinas Redes sociais para interação/aprendizagem e registros de memória e A Construção do Conhecimento na Contemporaneidade: Processo de aprendizagem para o mestrado em Educação com 20 estudantes. O Estudo de Caso compreende a tentativa de esclarecer uma decisão ou um conjunto de decisões, envolvendo o processo de aprendizagem, a interação entre os participantes, a copresença e a Educação online. Conforme Yin (2005) isso permite que a investigação realizada preserve as características holísticas e significativas dos acontecimentos da vida real. Portanto, um Estudo de Caso

é uma investigação empírica que pesquisa um fenômeno contemporâneo 
dentro de seu contexto da vida real, especialmente quando os limites entre o fenômeno e o contexto não estão claramente definidos.

Durante a investigação os estudantes foram convidados a expressar, nos diferentes espaços, os conhecimentos construídos, em processos de interação. Então, foram selecionadas algumas situações para refletir sobre o processo de aprendizagem, esses extratos foram mantidos no seu formato original, idênticos à escrita dos participantes. Os participantes da pesquisa assinaram o termo de consentimento livre e esclarecido e as identidades são preservadas por meio de pseudônimos. Os espaços digitais virtuais utilizados foram: os metaversos (Second Life), cuja representação é gráfica e metafórica; o ambiente virtual de aprendizagem (Moodle), redes sociais, tecnologias de compartilhamento, comunicadores instantâneos e aplicativos para dispositivos móveis. Também foram registradas em diário de campo as observações realizadas em sala de aula, espaço geográfico. Assim, os dados coletados constituem-se das observações e dos registros realizados nos espaços digitais virtuais e em sala de aula, ou seja, as representações dos participantes, carregadas de significados.

A abordagem qualitativa dos dados se dá por meio das interpretações atribuídas às situações vividas e registradas nas atividades propostas, considerando as unidades de análise encontradas no referencial teórico e nos próprios dados coletados, submetidos a Análise de Conteúdo (BARDIN, 2011). Para a reflexão sobre o processo de aprendizagem, foram mobilizadas as seguintes unidades de análise: perturbação, interação, legitimação do outro, configuração do espaço de convivência e significado no cotidiano.

\section{Reflexões sobre o processo de aprendizagem em espaços hibridos}

Ao articular o referencial teórico e as discussões realizadas no grupo de pesquisa, entende-se que o processo de aprendizagem, em espaços híbridos, a partir da presença dos estudantes, implica: na perturbação (estranhamento e relação entre o conhecimento já aprendido e o conhecimento novo), na interação (compartilhamento para compensar a 
perturbação), legitimação do outro (como alguém com quem eu posso aprender), configuração do espaço de convivência (identificação do que é significativo para o grupo) e superação (atribuir o significado ao conhecimento no cotidiano).

A presença dos estudantes, no processo de aprendizagem, ocorre pela ação cognitiva, compartilhada com os demais participantes. Ao compartilhar a presença, devido a nossa autonomia, segundo Maturana e Varela (2001), são identificadas proximidades, distanciamentos e diferenciações entre o que sabemos e o que está sendo compartilhado, a fim de construir o conhecimento no coletivo.

O compartilhamento das presenças entre os estudantes e entre estes e a educadora ocorre em espaços híbridos (geograficamente localizados e digitais virtuais) configurados nas relações estabelecidas em sala de aula e por meio de diferentes tecnologias digitais, tais como: fórum de discussão, chat, diário de aprendizagem, glossário, Google Docs, Prezi, Cmap Tools, Second Life, Movie Maker, videoconferência e Facebook. No Quadro 1, o processo de aprendizagem é apresentado na discussão dos estudantes da disciplina de Informática e Multimeios na Educação, destacando a dificuldade em instaurar a perturbação, o processo de interação, as particularidades da legitimação do outro e significado no cotidiano.

Quadro 1: Recorte do Fórum na disciplina "Informática e Multimeios na Educação" sobre "Redes Sociais".

Assunto: Redes Sociais

Estudante 1 - segunda, 18 agosto 2014, 20:31

Professora trabalho no Colégio Marista Pio XII em Novo Hamburgo e recentemente lançaram o Código de Conduta da escola. Neste lançamento eles apresentaram um vídeo De Boas Práticas nas Redes Sociais, da empresa Vale. Achei o vídeo bem interessante, e acredito que seja bem relevante para a disciplina pois fala sobre o que postar/publicar nas redes sociais e que tudo que postamos interfere também no nosso lado profissional. Se tiveres talvez algum tempo seria interessante mostrar ou disponibilizar aos colegas.

https://www.youtube.com/watch?v=56r_9MJ1DFg

Estudante 3 - quarta, 3 setembro 2014, 09:09

Achei muito interessante o vídeo. Acredito que será de grande valia Etrazer esse material para uma aula, pois serve para todos, seja como aviso ou informação. 


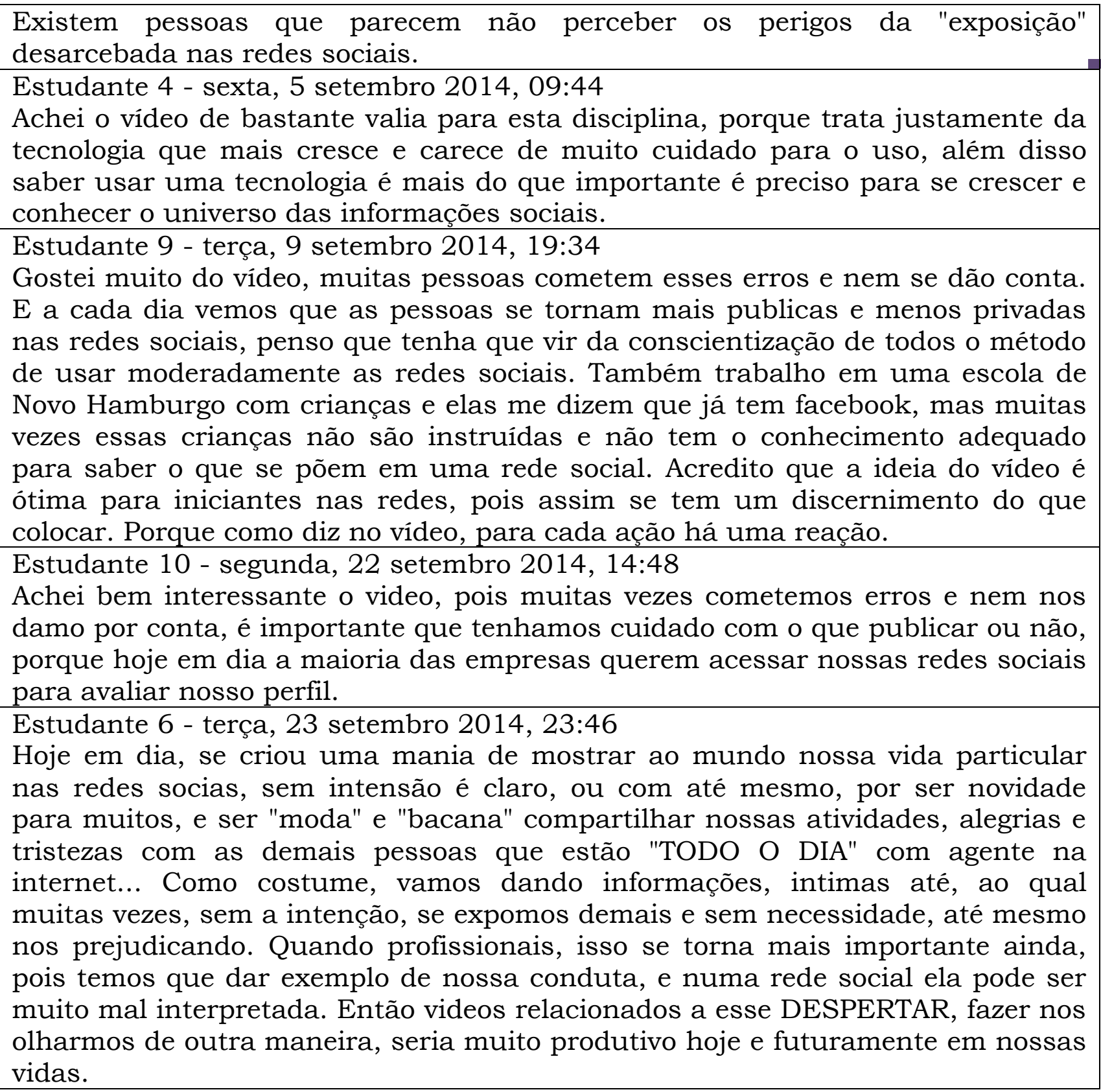

Fonte: Extrato do Ambiente Virtual de Aprendizagem Moodle.

Todos os estudantes se fizeram presentes somente uma vez, por meio de seus registros. Nenhum estudante propôs um questionamento ao grupo e todos os comentários foram dirigidos ao Estudante 1 (autor da proposição inicial). A proposição é direcionada para a educadora, que nesse momento não realizou mediação, a fim de compreender a forma de configuração do espaço de convivência do grupo. Na proposição o Estudante 1 destaca para a educadora a necessidade e relevância de compartilhar um vídeo com os colegas, sem perceber que ao postar no fórum já estaria compartilhando com 
os mesmos. O vídeo sugerido, descrito no extrato, desencadeou a perturbação nos colegas em relação à maneira de se apropriar dos espaços digitais virtuais e das redes sociais, atribuindo significado ao mesmo no seu cotidiano.

Com o intuito de potencializar o processo de interação, os Estudantes 3 e 4 legitimam o conhecimento compartilhado pelo Estudante 1 e identificam a importância e relevância do conhecimento para o contexto da disciplina e da atuação profissional. O fórum é utilizado como espaço de comunicação entre os estudantes, porém, não é tratado por todos como meio no qual se desenvolve a aula, o que evidenciamos a partir da ação do Estudante 3 em sugerir que um vídeo inserido no fórum seja trazido para a aula. Há dificuldade em reconhecer o espaço digital virtual como parte integrante de um espaço híbrido para a aprendizagem, mesmo que em nosso cotidiano isso aconteça naturalmente, como sugere o geógrafo Santos (2008).

O Estudante 9 se faz presente abordando elementos mais concretos do seu cotidiano articulando com os conhecimentos discutidos na disciplina. $\mathrm{O}$ Estudante 10 anuncia sua perturbação em relação aos possíveis erros que cometemos, mas não apresenta uma pergunta desafiadora aos seus colegas para que o fluxo de interação se intensifique entre eles, numa comunicação mais dinâmica e menos centrada no post inicial ou na educadora.

O Estudante 6, a partir de uma reflexão sobre a demasiada exposição nas redes sociais, representa seu desequilibrio, ponderando possiveis consequências desta atitude e articulando com o meio profissional, atribuindo significado ao cotidiano. O estudante, sem manter o fluxo da interação com os colegas, busca uma solução para mudar este contexto. Como alternativa propõe a criação de vídeos relacionados às mudanças de conduta perante às redes, o que chama de "Despertar", com o intuito de possibilitar uma conscientização. Observa-se que o processo de perturbação sobre uma determinada situação também pressupõe a criação de alternativas às situações que provocaram este desequilíbrio. 
Para o compartilhamento da presença e o desencadeamento da perturbação, os estudantes precisam estar em interação. A interação, no contexto pedagógico, implica em diálogo para potencializar a construção de conhecimento entre estudantes e entre estudantes e educador, em congruência com o meio. Nessa interação o estudante conserva sua identidade (no âmbito individual) e configura o espaço de convivência (no âmbito coletivo). Em resumo, a interação ocorre num espaço de convivência, onde os estudantes compartilham suas presenças com o outro, conforme sua história construída ao longo de sua vida, desencadeiam perturbações e compensam essas perturbações, que resultam em transformação.

No entanto, no fórum de discussão, o processo de interação se configurou de forma linear, com poucas articulações e atravessamentos entre as representações dos colegas, mesmo que houve a legitimação. Percebe-se a preocupação em atribuir significado ao conhecimento no cotidiano dos estudantes, estabelecendo relações com as experiências enquanto estudantes e profissionais. Sem a mediação da educadora, nesse fórum de discussão, não foi possivel evidenciar a configuração do espaço híbrido de convivência, os estudantes representaram as suas percepções, mas as interações não foram dinâmicas, as perturbações não foram expressas de forma clara, logo não houve a coordenação das ações entre os participantes.

A dinâmica do processo de interação pode ser evidenciada na Figura 1, para a escrita de texto coletiva, proposta na disciplina "Redes sociais para interação/aprendizagem e registros de memória". Um documento foi criado e compartilhado entre os estudantes para a construção do conhecimento referente à "Cultura e Cibercultura: a educação na era digital". Nessa atividade compreendemos de que forma ocorre a configuração do espaço de convivência entre os estudantes.

Figura 1 - Escrita de texto coletiva na disciplina "Redes sociais para interação/aprendizagem e registros de memória". 


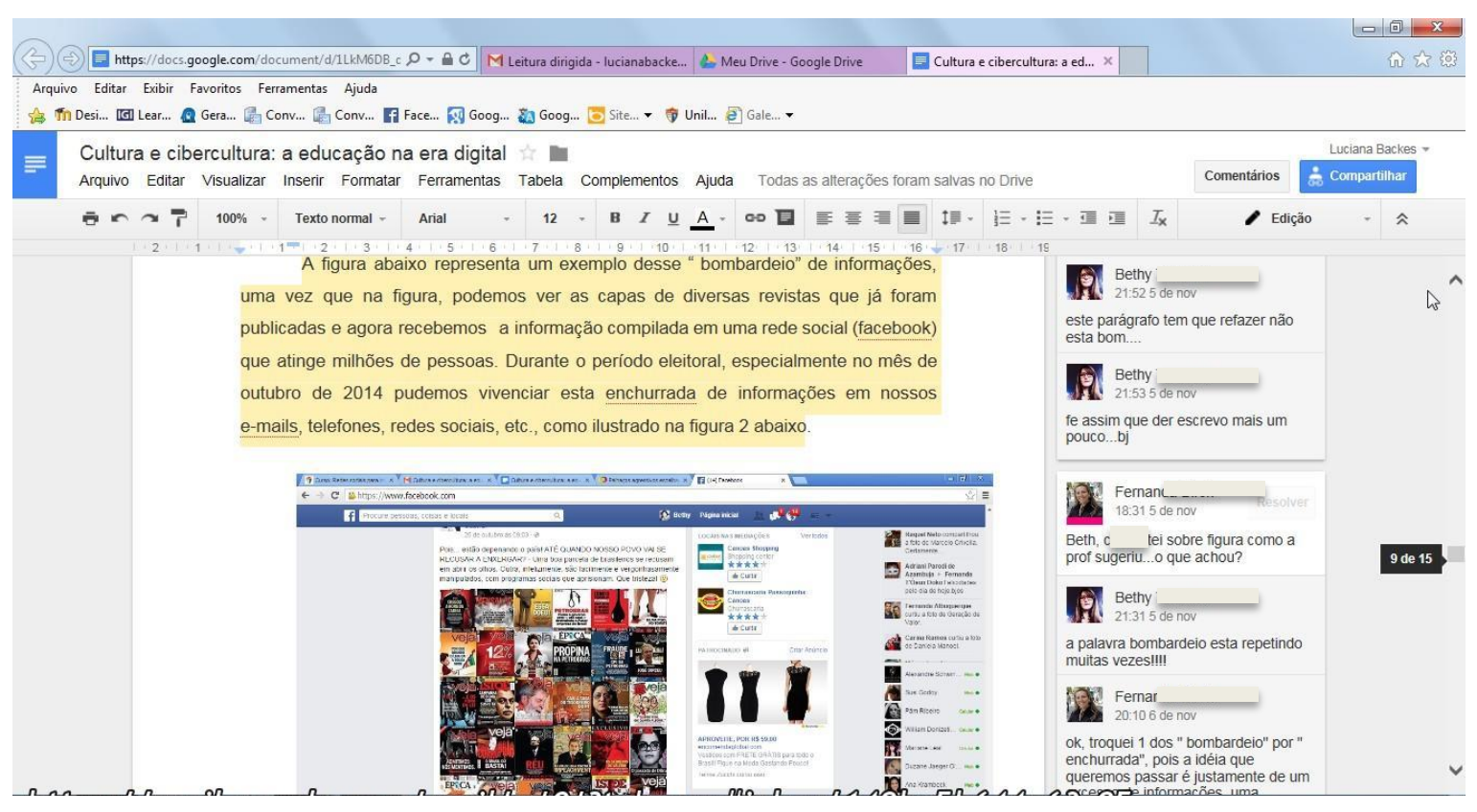

Fonte: Captura da plataforma Google Docs.

Os participantes se fazem presentes nas representações do texto, assim como nos comentários registrados no frame à direita da tela. Os comentários são utilizados para expressar as perturbações, assim como as interações para compensar as perturbações. As perturbações apresentadas são referentes à temática e aos aspectos linguísticos. Em todo o momento as representações dos estudantes são legitimadas pelos mesmos, seja em relação ao conhecimento, forma de escrita e perturbações expressas. No texto evidencia-se a sistematização dos conhecimentos e a relação com o cotidiano dos estudantes, capturando imagens das redes sociais e discutindo o momento político vivenciado.

Também podemos destacar a menção sobre a mediação pedagógica da educadora em um dos comentários. Assim, evidencia-se a configuração do espaço de convivência, pois os estudantes representam suas percepções, compartilham informações e conhecimentos, expressam as perturbações, interagem e aprendem, transformando a si mesmos, assim como o espaço digital virtual e a estrutura linguística do texto, com imagens e discussões de redes sociais. Na configuração desse espaço de convivência o processo de aprendizagem resulta na criação de uma novidade no contexto acadêmico, 
as múltiplas linguagens e a potencialização da interação nos comentários disponibilizado no Google Docs.

Diferentemente do que observamos no fórum retratado no Quadro 1, a escrita de texto coletiva seguiu uma forma menos linear de participação. No Google Docs, todos os estudantes poderiam acrescentar, excluir ou sugerir alterações em qualquer parte do material produzido, fazendo com que essa se torna uma forma mais dinâmica de interação e caracterizando o espaço de convivência. A análise destas duas formas de participação faz emergir a percepção de que nem todo o espaço digital virtual é configurado como um espaço de convivência. Diferentes meios (ou contextos) potencializam a interação entre os participantes de maneiras distintas, assim como as práticas pedagógicas planejadas. O fórum, mesmo que praticado pelos estudantes no seu cotidiano não resulta numa construção em um único espaço coletivo, diferentemente do arquivo único criado no Google Docs.

Ao longo do processo de aprendizagem, valorizam-se as trajetórias de interações que os estudantes trazem de sua vivência, resultando na sua transformação por meio de um elemento perturbador interno (suas reflexões) ou externo (educador ou colega). A apropriação dos espaços digitais virtuais de uso individual, como destacado no Quadro 2, demonstra, no caso do estudante 11 , a exploração do conceito de hibridismo, por meio de ações também híbridas, articulação entre as discussões realizadas nos diferentes espaços digitais virtuais e nos espaços geográficos.

Quadro 2: Diário de aprendizagem na disciplina "Redes sociais para interação/aprendizagem e registros de memória”.

\section{Estudante 11}

Data: $19 / 11$

Esta aula foi explorada a partir dos textos propostos pela professora sobre Hibridismo tecnológico e Espaço de convivência digital virtual e seus processos de interação e convivência. As duas obras são de sua autoria e tratam da importância e da intensidade da tecnologia digital virtual na contemporaneidade e nos espaços de convivência. Espaços que tornam-se colaborativos para a construção do conhecimento e da educação por meio do hibridismo tecnológico digital. Estas interações podem acontecer em diferentes espaços digitais, tanto dentro como fora da escola, relação que acontece em congruência de conduta, ou 
seja, busca-se uma convivência de aceitação mútua. Esta aceitação se dá po meio do respeito e consiste em aceitar o outro como legítimo na convivência. Aફ tecnologias trazidas pelo texto nos possibilitam perceber o quanto somos rodeados e o quanto sua utilização esta imbricada em nosso dia a dia. Oportunizando um conjunto de ações e interações entre os sujeitos, sejam elas, textuais, gráficas ou orais.

06/01: Entendo por hibridismo tecnológico digital, os diferentes espaços digitais virtuais que, a partir de seu crescimento tecnológico, amplificam a possibilidade de transformar e construir as diferentes formas de viver, conviver e coexistir. Esta integração se articula e ganha força independente do espaço geográfico que cada usuário se encontra ou o tipo de tecnologia que utiliza. $O$ que se faz premente é justamente a interação e a comunicação.

Olá Estudante 11

Muito bom o teu registro! Gostaria apenas que complementasse escrevendo o que tu entendeste por Hibridismo Tecnológico Digital.

Abraços

Educador

Fonte: Extrato do Ambiente Virtual de Aprendizagem Moodle.

No texto do quadro 2 , o estudante 11 reconhece o hibridismo ao mencionar a coexistência de dois espaços, caracterizando a configuração dos espaços híbridos de aprendizagem, no caso, os ambientes virtuais de aprendizagem, através de uma mescla entre os conhecimentos construídos em atividades online (espaço digital virtual) e em atividades off-line (espaço geograficamente localizado), legitimando os textos de autoria do Educador. O Estudante atribui significado ao afirmar que "o ciberespaço proporciona a criação de espaços diversos que oportunizam a participação dos sujeitos”, destacando a interação no ambiente virtual de aprendizagem e na sala de aula, mediada pelo Educador. Percebemos ainda a problematização do estudante acerca do chamado espaço de relação (MATURANA, 2002) como espaços nos quais se buscam congruência de conduta e aceitação mútua.

O estudante 11 representa os conhecimentos explorando os artigos propostos em aula, sem ampliar sua percepção. Nesse momento, o educador media o processo a partir de uma perturbação. O estudante, ainda bastante atrelado ao texto, consegue trazer um novo elemento para a discussão referente a comunicação, sem aprofundar a temática. Nessa interação, destaca-se a importância da mediação pedagógica, possibilitada pelos Interfaces da Educ., Paranaíba, v.11, n.32, p. 542 - 570, 2020 
recursos (dispositivos e internet), que potencializam os espaços híbridos, através de experiências que consideram as diferentes formas de aprender.

Para Backes (2015), o hibridismo tecnológico digital resulta num conjunto de tecnologias digitais coerente de possibilidades de realização da atividade humana num espaço digital virtual. Assim, através das interações pode proporcionar um maior engajamento do aluno nas experiências de aprendizagem ligadas, resultantes da mistura de ambientes, para a construção do conhecimento.

$\mathrm{Na}$ construção do conceito de "adaptação", por meio do recurso do Glossário disponível no Moodle, identificado pelos estudantes como sendo conceito-chave para a disciplina "Informática e Multimeio na Educação", a estudante 12, utilizou como referência Piaget para expressar suas compreensões sobre o conceito e iniciar o processo de interação com os seus colegas. O processo de aprendizagem dos estudantes, foi baseado nos conhecimentos teóricos estudados na disciplina, os registros seguem as referências bibliográficas, assim como a lógica e os vocabulários explorados pelos autores.

Quadro 3: Glossário proposto na disciplina "Informática e Multimeios na Educação"

Assunto: Adaptação

Estudante 5

Piaget dizia que adaptação é uma característica fundamental do ser humano, seu desenvolvimento intelectual e biológico depende deste fator, nestes dois processos de desenvolvimento temos um prolongamento entre eles, no sentido que precisamos estar sempre nos adaptando às novas informações, novos ambientes e a novos conhecimentos.

Neste processo de adaptação encontramos a assimilação e a acomodação.

Estudante 15 - Seg, 10 Nov 2014, 19:26

A adaptação é uma das qualidades inerentes ao ser humano. Ela faz parte do nosso processo de evolução. Provavelmente é por causa dela que nós estamos aqui hoje :)

Educadora - Seg, 10 Nov 2014, 20:15

Estudante 5, no teu registro há a seguinte afirmação "nestes dois processos de 
desenvolvimento temos um prolongamento entre eles". Quais são esses dois processos? O que significa o prolongamento entre eles?

Estudante 5 - Ter, 11 Nov 2014, 10:36

Esses dois processos de desenvolvimento são o biológico onde eu me adapto ao ambiente e aprendo a viver no coletivo e ao cognitivo onde eu estarei adaptando meus conhecimento adquiridos.

Quando digo que há um prolongamento entre eles, digo que primeiramente preciso me adaptar ao meio onde estou inserido, para depois me adaptar cognitivamente, pois é neste meio que eu vou retirar conhecimento ,informações e é desta forma de eu vou interagir com o mundo externo, ou seja com o meu entorno

Fonte: Extrato do Ambiente Virtual de Aprendizagem Moodle.

Inicialmente a estudante 5 registrou um conceito incompleto e pouco conciso para a "adaptação", abordou outros conceitos que estão vinculados. Não houve manifestação de perturbações e tão pouco atribuiu significado do conhecimento no cotidiano. A estudante 15 amplia o conceito relacionando com a nossa história de evolução, para iniciar a interação. Da mesma forma, não manifesta perturbação e não atribui significado do conhecimento no cotidiano, mas evidencia-se a legitimação em relação ao registro da Estudante 5.

Então, a educadora identifica a fragilidade do conceito e mesmo com a ampliação da estudante 15, não é possivel evidenciar o que as estudantes aprenderam sobre o mesmo, o processo de aprendizagem parece uma reprodução dos conhecimentos teóricos. Para tanto, faz-se necessária a perturbação, provocada pela articulação com o que estava registrado e perguntas problematizadoras. Nesse sentido, podemos evidenciar que a estudante 5 foi pesquisar mais elementos, considerando o que a colega registrou em relação a evolução do desenvolvimento humano, articulou o conceito de "adaptação" aos aspectos biológicos e cognitivos.

Algumas das dificuldades evidenciadas no processo de aprendizagem e apontadas nas análises podem estar relacionadas, entre tantos outros fatores, às práticas pedagógicas desenvolvidas ao longo da história de cada estudante, fundamentadas na compreensão de que a origem do conhecimento tem uma perspectiva epistemológica racionalista, empirista Interfaces da Educ., Paranaíba, v. 11, n.32, p. 542 - 570, 2020 
e/ou apriorista, segundo Hessen (2003) e Becker (2012). Portanto, ao longo da nossa história de aprendizagem, a perturbação e a interação não foram contempladas e tão pouco potencializadas. No Quadro 4 podemos perceber a forma como os estudantes participam de maneira dirigida.

Quadro 4: Fórum de discussão proposto na disciplina "Informática e Multimeios na Educação".

Assunto: Ciberespaço

Estudante 12 - quarta, 13 agosto 2014, 19:49

Ciberespaço é um espaço existente no mundo de comunicação em que não é necessária a presença fisica do homem para constituir a comunicação como fonte de relacionamento,onde todas as tecnologias possibilitam criar encontro.

Educadora - domingo, 17 agosto 2014, 09:04

Estudante 12, te convido a participar da discussão criada pela Estudante 13 !! Educadora

Estudante 12- terça, 30 setembro 2014, 20:35

Achei interessante o conceito apresentado pela Estudante 13, principalmente que não precisamos estar físicamente com outro ser humano, mas estamos conectados com o mesmo virtualmente.

Fonte: Extrato do Ambiente Virtual de Aprendizagem Moodle.

Nesse caso, a estudante 12 estava preocupada em responder a problemática do fórum de discussão proposto pela educadora, ou seja, cumprir a atividade proposta, sem considerar as interações já realizadas pelos demais estudantes. A educadora problematiza o processo de interação não realizado (considerando essa temática pertinente ao ciberespaço) estabelecendo relação com o comentário da Estudante 13. A estudante 12 legitima a problematização, sem interagir com o colega, retoma a sua discussão (no seu espaço de origem), configurado individualmente, para articular suas ideias com as ideias postadas no fórum da estudante 13. A estudante 12 apresentou dificuldade em compreender que essa interação poderia ser feita com os demais colegas, assim como ela poderia ter explorado as interações para além da proposta da estudante 13. 
O processo de interação ocorre realmente quando se aceita o colega ou o docente como alguém com quem se pode aprender, ou seja, alguém que contribui com ideias, amplia e/ou problematiza o conhecimento que se compartilha. Portanto, para o processo de aprendizagem, por meio da interação, é fundamental a legitimidade do outro. O colega pode ser legitimado quando sua contribuição é discutida, ampliada, o docente é legitimado quando a sua pergunta é respondida ou quando os estudantes agem de maneira comprometida em relação à proposta pedagógica.

No modelo de educação que se tem desde a educação básica, não é comum legitimar os discursos vindos dos estudantes e o educador é considerado, muitas vezes, o único detentor do conhecimento. As práticas pedagógicas são pouco problematizadoras e dão ênfase ao conteúdo. Compreende-se a educação online como possibilidade de conectar diferentes participantes, ultrapassar os limites geográficos e problematizar os conhecimentos, aproximando-os da realidade dos estudantes por meio de diferentes linguagens.

\section{Considerações finais}

Os estudantes participam desse mundo tecnologizado, por meio de emails, redes sociais, comunicadores instantâneos, jogos eletrônicos, sites, blogs, entre outros espaços digitais virtuais disponiveis na rede da internet. $\mathrm{Ou}$ ainda, participam de maneira mais direta realizando operações bancárias, compras online, localizando artigos, lendo notícias, tirando fotografias e compartilhando vídeos. Assim, vivem a cibercultura tanto de maneira direta como indireta, participando da construção do fluxo da rede ou apenas seguindo, sem muitos questionamentos ou críticas.

Nesta convivência permeada por artefatos tecnológicos, natureza e cultura, atribuem diferentes significados aos conhecimentos, reinventando o cotidiano, tempos e espaços, potencializando a criação de trajetórias de aprendizagem pessoais para cada ser humano. 
Muitas vezes, nas interações propiciadas durante as atividades em aula, os estudantes fazem críticas às pessoas que estão conectadas aos seus celulares, que expõem suas vidas nas redes sociais e ainda falam sobre alguns cibercrimes envolvendo celebridades. Entretanto, em um contexto híbrido, esses estudantes também se encontram conectados, e por meio de leituras hipertextuais localizam informações a qualquer momento, utilizam diferentes aplicativos do celular de maneira articulada e comunicam-se com seus amigos próximos e distantes. Tudo isso, sem perceber a articulação entre os discursos e as práticas.

Mas o que acontece com esses estudantes quando desenvolvem seus processos de aprendizagem na educação online?

O processo de aprendizagem é desencadeado a partir da manifestação do estudante em relação a uma determinada temática, para tanto precisa se fazer presente nessa ação. Em alguns momentos os estudantes se fazem presentes a partir da percepção de um autor, ou reproduzindo a percepção do educador, alguém que para ele é legitimo em relação ao conhecimento. $\mathrm{Na}$ educação online é potencializado o compartilhamento dessa presença de maneira autoral, a fim de identificarmos diferenças e estranhamentos, emergindo a perturbação, que ocorre também na relação entre o conhecimento já aprendido e o conhecimento novo. Dessa forma, é possível manter o fluxo de interação entre os estudantes, o educador $\mathrm{e} o$ conhecimento em congruência com os espaços (cada vez mais híbridos), a fim de compensar a perturbação.

Nem sempre os estudantes se autorizam a fazer perguntas, em alguns casos apresentam dificuldade em questionar. A preocupação maior parece estar em dar uma boa resposta, ou a resposta que para a turma seja considerada correta. Também evidenciamos que a legitimação do outro, como alguém com quem eu posso aprender, está centrada no educador e dificilmente ocorre em relação ao colega.

Logo, apesar de as TD potencializarem a autoria, a comunicação, a hipertextualidade, a ubiquidade e a conectividade e esses conceitos estarem 
presentes no cotidiano dos estudantes conforme mencionado anteriormente, ainda é um desafio a configuração do espaço híbrido de convivência nas práticas pedagógicas da educação online. Mais do que propor práticas em congruência com o mundo contemporâneo, é necessário estabelecer mediação pedagógica para que se possa identificar o que é significativo para os estudantes, promover a autoria dos mesmos e, principalmente, tomar consciência do seu processo de aprendizagem nesses espaços. Dessa forma, no processo de aprendizagem, será possível aos estudantes estabelecer significado no cotidiano, ou seja, compreender o conhecimento a partir do viver e conviver.

\section{Referências}

BACKES, L. 2007. A Formação do Educador em Mundos Virtuais: Uma investigação sobre os processos de autonomia e de autoria. $186 \mathrm{p}$. Dissertação (Programa de Pós-Graduação em Educação) - Universidade do Vale do Rio dos Sinos - UNISINOS, São Leopoldo - Brasil).

\section{BACKES, L. 2011. A Configuração do Espaço de Convivência Digital}

Virtual: A cultura emergente no processo de formação do educador. 362 p. Tese (Programa de Pós-Graduação em Educação) - Universidade do Vale do Rio dos Sinos - UNISINOS, São Leopoldo, Brasil - cotutela em Science de l'Education, Université Lumière Lyon 2, Lyon, France.

BACKES, L. 2013. Hibridismo tecnológico digital: configuração dos espaços digitais virtuais de convivência. In: III Colóquio Luso-Brasileiro de Educação a Distância e E-Learning. Lisboa, Portugal.

BACKES, L. 2015. O Hibridismo Tecnológico Digital na configuração do espaço digital virtual de convivência: formação do educador. Inter Ação, vol. 40 n. 3. Goiânia, Set - Dez, 2015, p. 435 - 456. Disponível em $<$ http://dx.doi.org/10.5216/ia.v40i3.35419>

BACKES, L.; SCHLEMMER, E. 2014. O Processo de Aprendizagem em Metaverso: Formação para emancipação digital. Desenvolve Revista de Gestão do Unilasalle, v. 3, p. 47-64. Disponível em $<$ https://revistas.unilasalle.edu.br/index.php/desenvolve/article/view/138 $7 / 1031>$

BACKES, L.; SCHLEMMER, E.; RATTO, C. G. 2017. A convivência de natureza digital virtual nas tribos: formação na perspectiva do hibridismo tecnológico digital. Revista Ibero-Americana de Estudos em Educação, v. 
12 , p. $\quad 1194-1216$.

Disponivel

em

<https://doi.org/10.21723/riaee.v12.n.esp.2.9881>

BARDIN, L. 2011. Análise de Conteúdo. 4. ed. Lisboa: Edições 70.

BECKER, F. 2012. Educação e construção do conhecimento. 2. ed. Porto Alegre: Penso.

HESSEN, J. 2003 Teoria do conhecimento. São Paulo: Martins Fontes.

LATOUR B. 1991. Jamais fomos modernos. São Paulo: Editora 34.

LÉVY, J. LUSSAULT, M. 2003. Dictionnaire de la géographie et de l'espace des sociétés. Paris: Belin.

LÉVY, P. 1996. O Que é Virtual? São Paulo: Editora 34.

LOMBARD, M.; DITTON, T. 1997. At the heart of it all: The concept of presence. Journal of Computer Mediated-Communication, v 3, Issue 2, 1 September, JCMC321. Disponivel em: <https://doi.org/10.1111/j.10836101.1997.tb00072.x>

MAFFESOLI, M. 2012. O tempo retorna: Formas elementares da pósmodernidade. Rio de Janeiro: Forense Universitária.

MATURANA, H. R.1993a. Uma nova concepção de aprendizagem. Dois Pontos, Belo Horizonte, v. 2, n.15 (jan./jul. 1993) p. 28-35.

MATURANA, H. R.1993b. As bases biológicas do aprendizado. Dois Pontos, Belo Horizonte, v. 2, n.16, p. 64-70, ago./dez.

MATURANA, H. R.1999. Transformación em la Convivência. Santiago de Chile: Dólmen Ediciones, 1999.

MATURANA, H. R. 2002. A Ontologia da Realidade. Belo Horizonte: Editora UFMG.

MATURANA, H. R.; VARELA, F. J. 1997. De máquinas e seres vivos: Autopoieses - a organização do vivo. 3 ed. Porto Alegre: Artes Médicas.

MATURANA, H. R.; VARELA, F. J. 2001. A árvore do Conhecimento: As bases biológicas da compreensão humana. 2. ed. São Paulo: Palas Athena.

MORAES, M. C. 2004. O paradigma educacional emergente. 10.ed. Campinas, SP: Papirus, 2004. 
SANTOS, B. S. 2004. Um discurso sobre as ciências. 2.ed. São Paulo: Cortez.

SANTOS, E. O.; WEBER, A. 2014. Diários online, cibercultura e pesquisaformação multirreferencial. In: Edméa Santos. (Org.). Diário Online: dispositivo multirreferencial de pesquisa-formação na cibercultura. 1ed. Santo Tirso: Whitebooks, v. 1, p. 13-31.

SANTOS, E. O.; SILVA, M. 2009. O desenho didático interativo na educação online. Revista Iberoamericana de Educación (Online), v. 49, p. 267-287.

SANTOS, E. O. 2009. Educação online para além da EAD: um fenômeno da cibercultura. $X$ Congresso Internacional Galego-Português de Psicopedagogia. Anais... Braga: Centro de Investigação em Educação da Universidade do Minho.

SANTOS, M. 1980. Por uma geografia nova. Da crítica da Geografia a uma Geografia crítica. São Paulo: Editora Hucitec.

SANTOS, M. 2008. A natureza do espaço: Técnica e tempo, razão e emoção. 4. ed. São Paulo: Editora da Universidade de São Paulo.

SANTOS, M. 2014. Metamorfoses do espaço habitado: fundamentos teóricos e metodológicos da geografia. 6. ed. São Paulo: Editora da Universidade de São Paulo.

SCHLEMMER, E.; BACKES, L.; ROCCA, F. L. 2016. L'Espace de coexistence hybride, multimodal, pervasif et ubiquitaire: Le quotidien de l'éducation à la citoyenneté. Educação UNISINOS (ONLINE), v. 20, p. 299-308. Disponivel em <https://doi.org/10.4013/edu.2016.203.03>

SILVA, M. 2014. Sala de aula interativa. Rio de Janeiro: Quarter.

TREIN, D. 2010. Educação Online em Metaverso: A mediação pedagógica por meio da telepresença e da presença digital virtual via avatar em Mundos Digitais Virtuais em 3 Dimensões. 224 p. Dissertação (Programa de PósGraduação em Educação) - Universidade do Vale do Rio dos Sinos UNISINOS, São Leopoldo - Brasil).

YIN, R.K. 2005. Estudo de caso: Planejamento e métodos. 3. ed. Porto Alegre: Bookman. 